\title{
A formação de instrutores de Libras: a consolidação das políticas linguísticas na Amazônia tocantina
}

\author{
Training of Libras instructors: consolidation of linguistic policies in the \\ Amazon region of Tocantins
}

Formación de instructores de Libras: consolidación de las políticas lingüísticas en la región Amazónica de Tocantins

\author{
Waldma Maira Menezes de Oliveira \\ Doutoranda na Universidade do Estado do Pará, Pará, Brasil. \\ waldmamaira@hotmail.com \\ ORCID - https://orcid.org/0000-0002-8747-5185
}

Ivanilde Apoluceno de Oliveira

Professora doutora na Universidade do Estado do Pará, Pará, Brasil.

nildeapoluceno@uol.com.br

ORCID - https://orcid.org/0000-0002-3458-584X

Recebido em 25 de maio de 2019

Aprovado em 22 de agosto de 2019

Publicado em 22 de outubro de 2019

\section{RESUMO}

O estudo apresenta registros e reflexões sobre as políticas linguísticas na Amazônia Tocantina no que tange à formação de instrutores de Libras. As políticas linguísticas apresentam raízes nas políticas públicas e, ao pensar nelas no campo da surdez, enfatiza-se a importância de um espaço e de uma educação bilíngue para Surdos e profissionais capacitados em Libras - instrutores e intérpretes. Por tratar desse objeto, o Grupo de Estudos Surdos na Amazônia Tocantina (GESAT) propôs, em 2017, a formação de instrutores de Libras com o intuito de formar profissionais para o ensino de Libras nas escolas do Campo e reafirmar as políticas linguísticas no campo das diferenças. $O$ objetivo deste estudo é analisar as contribuições do curso na formação e capacitação deste profissional e de maneira específica, problematizar a atuação dos instrutores de Libras Surdos enquanto modelo linguístico e identitário. Realizou-se uma pesquisa de campo de abordagem qualitativa com ênfase na Teoria das Representações Sociais de característica processual de Moscovici (2009). Os entrevistados foram quatro Surdos egressos da formação. Nos resultados observou-se que os entrevistados marcaram sua atuação como consolidação das políticas públicas e linguísticas na área da Libras e como modelo identitário para o ensino de Surdos, pautado no reconhecimento da diferença na alteridade e no bilinguismo.

Palavras-chave: Políticas linguísticas; Instrutores de Libras; Representações sociais. 
http://dx.doi.org/10.5902/1984686X38279

\section{ABSTRACT}

This research presents registers and reflections about linguistic policies in the Amazon region of Tocantins, which referencing to the training of Libras instructors. Linguistic policies establish/ founded/ based on public policies, when thinking about them, specifically in the deafness field; it is necessary to emphasize the importance of a space and a bilingual education for deaf and trained professionals in Libras - instructors and interpreters. To study this target, the Studies Group of Deaf in the Amazon Region of Tocantins (Grupo de Estudos Surdos na Amazônia Tocantina - GESAT), proposed the Libras's Instructor Course in 2017, with the purpose to train professionals for teaching Libras at Field schools and reaffirm linguistic policies in the scope of differences. The aim is analyze the course's contributions during the training and qualification of this professional and, specifically, to problematize the performance of the deaf Libras's Instructor as a linguistic and identity model. For this study, a field investigation was executed with a qualitative approach, with emphasis on the Theory of Social Representations of Moscovici's procedural characteristic (2009). In addition, four deaf students for the course were interviewed. In the results, it was observed that the interviewees marked their performance as: consolidation of public and linguistic policies in Libras's area and as a model of identity for teaching the deaf, aimed at the recognition of difference as alterity and bilingualism.

Keywords: Linguistic policies; Libras's instructor; Social representations.

\section{RESUMEN}

El presente estudio presenta registros y reflexiones sobre las políticas lingüísticas en la región amazónica de Tocantins concerniente a la formación de instructores de Libras. Las políticas lingüísticas se fundamentan en las políticas públicas, al pensar en ellas, en el campo de la sordez, se enfatizan: la importancia de un espacio y una educación bilingüe para los sordos y los profesionales capacitados en Libras - instructores e intérpretes. Por abordar este objeto de investigación, el Grupo de Estudios de Sordos en la Región Amazónica de Tocantins (GESAT), propuso, en el año 2017, el curso de instructor de Libras, con el fin de formar profesionales para la enseñanza de Libras en las escuelas del Campo y reafirmar las políticas lingüísticas en el ámbito de las diferencias. El objetivo de este estudio es analizar las contribuciones del curso durante la formación y capacitación de este profesional y, de manera específica, problematizar la actuación de los instructores de Libras sordos como modelo lingüístico y de identidad. Para este estudio, se realizó una investigación de campo con un abordaje cualitativo, con énfasis en la Teoría de las Representaciones Sociales de característica procesual de Moscovici (2009); además, fueron entrevistados cuatro egresados sordos del propio curso. En los resultados se observó que los entrevistados marcaron su actuación como: consolidación de las políticas públicas y lingüísticas en el área de Libras y como modelo de identidad para la enseñanza a los sordos, direccionado al reconocimiento de la diferencia como la alteridad y el bilingüismo.

Palabras clave: Políticas lingüísticas; Instructores de Libras; Representaciones sociales. 
http://dx.doi.org/10.5902/1984686X38279

\section{Introdução}

O Surdo ${ }^{1}$ vivencia um contexto educacional desfavorável para o desenvolvimento de suas potencialidades linguísticas, uma vez que o ambiente escolar não é propício para sua aprendizagem e nem para sua construção identitária pela falta de condições estruturais, entre as quais estão a falta de intérprete, situações atitudinais de discriminações, entre outras.

Assim, ao pensar na educação de Surdos na conjuntura da educação inclusiva, devem-se consideradar as especificidades linguísticas inerentes a esses sujeitos. Isto significa que o educando Surdo deve conviver em um ambiente bilíngue que favoreça a construção de sua identidade e valorize a sua comunicação por meio da Libras.

Desse modo, faz-se necessário construir um ambiente acolhedor, dialógico e bilíngue para que as potencialidades do Surdo sejam atendidas e para seu desenvolvimento seja, de fato, efetivado mediante o reconhecimento de suas singularidades linguísticas e identitárias. Porém, pesquisas apontam que a educação inclusiva desconsidera as especificidades linguísticas dos Surdos e não dispõe de práticas pedagógicas que favoreçam a sua aprendizagem, não possibilitando um ambiente efetivamente bilíngue (LACERDA, 2000; DORZIAT, 2009; LIMA, 2011).

Entende-se que estar no mesmo ambiente convivendo com os ouvintes não significa que o Surdo esteja vivenciando a inclusão, haja visto que se pode estar em um ambiente e não ter acessibilidade linguística e pedagógica. É pertinente mencionar a criação de um ambiente bilíngue como a primeira medida realizada para inclusão do educando Surdo no espaço educativo. Entretanto, outras medidas são necessárias para possibilitar uma efetiva inclusão educacional e linguística como: currículo flexível, práticas pedagógicas inclusivas, metodologias diferenciadas, etc. Os educandos Surdos precisam ter seus direitos linguísticos respeitados. Para isso acontecer, é imprescindível a presença de profissionais bilíngues no espaço educacional como: educadores bilíngues, intérpretes educacionais e instrutores de Libras.

O objetivo deste artigo é problematizar e refletir sobre as políticas linguísticas na Amazônia tocantina no que tange à formação de instrutores de Libras, tendo por base uma experiência extensionista com a formação de instrutores de Libras na região Amazônica. 
http://dx.doi.org/10.5902/1984686X38279

O Grupo de Estudos Surdos na Amazônia Tocantina (GESAT), vinculado à Faculdade de Educação do Campo, da Universidade Federal do Pará (UFPA), Campus Cametá, propôs, em 2017, a formação de instrutores de Libras com o intuito de formar profissionais para o ensino de Libras nas escolas do campo e reafirmar as políticas linguísticas no âmbito das diferenças. Em torno dessa formação, situa-se o problema investigado: quais as representações sociais dos egressos Surdos do curso de formação sobre a consolidação das políticas linguísticas a partir de sua atuação como instrutores de Libras?

Este artigo apresenta-se, a priori, sinalizando com o GESAT e destacando as principais informações sobre o curso de formação de instrutores de Libras. Em seguida, tem-se a metodologia sinalizada e, por fim, os resultados e discussões, contendo as categorias temáticas elaboradas.

\section{Sinalizando com o GESAT}

O GESAT² vem realizando, desde 2015, atividades de ensino, pesquisa e extensão, envolvendo a Associação de Surdos, graduandos, pesquisadores, professores e comunidade geral da Amazônia tocantina ${ }^{3}$ nas formações em torno do sujeito Surdo, da Língua Brasileira de Sinais e da Educação Especial no Campo, em torno de seis linhas de pesquisa: Práticas Pedagógicas de Libras no Ensino Superior; Movimentos Sociais e Surdez; Estudos em Educação, Surdez e Libras; Educação Inclusiva no Campo; Representações Sociais e Surdez; Aspectos Linguísticos da Libras.

O projeto intitulado "Formação de instrutores de Libras na Amazônia tocantina" foi vinculado ao GESAT, na linha de pesquisa: Educação, Surdez e Libras da UFPA Campus Cametá, no ano de 2017, com o objetivo de promover formação mediante a oferta de conhecimentos teóricos e práticos, na perspectiva de formar instrutores de Libras, que contribuíssem para a educação e a acessibilidade de pessoas surdas na Amazônia tocantina.

Oliveira (2017) considera necessário investir na formação de Instrutores de Libras competentes, éticos e reflexivos sobre seu papel social e educacional, para atenderem de forma eficaz à necessidade de ensino e de disseminação da Libras, a qual, embora reconhecida oficialmente pela Lei no 10.436/2002, ainda é desconhecida pela maioria dos profissionais da rede pública de ensino na Amazônia tocantina ${ }^{3}$. 
http://dx.doi.org/10.5902/1984686X38279

O curso de Instrutores de Libras na Amazônia tocantina foi realizado no município de Cametá ${ }^{4}$ no período de fevereiro a junho de 2017 com os seguintes módulos: a) Libras I, b) Libras II, c) Didática da Libras e da Língua Portuguesa como L2, d) Materiais em Libras, e) Literatura Surda e f) Introdução à Escrita de Sinais. Destaca-se que todos os professores que ministram os módulos dos cursos eram Surdos pertencentes ao movimento social Surdo e profissionais no ensino da Libras no âmbito da educação básica e superior.

Cada módulo apresentava uma carga horária de 36 horas e as atividades foram realizadas nos encontros presenciais, duas vezes ao mês, na quinta e sexta-feira. O curso iniciou com um quantitativo de 57 alunos dos seguintes municípios do Pará: Abaetetuba, Belém, Cametá, Igarapé-Miri, Mocajuba, Limoeiro do Ajuru, Oeiras do Pará e Tucuruí.

O perfil do público atendido centrou-se em 04 eixos: especialistas em Libras (20\%), sujeitos provenientes dos cursos básicos de Libras (50\%), atuação informal como instrutores de Libras (15\%) e sujeitos surdos (15\%) (OLIVEIRA, 2017). Ao término do curso foi realizada uma prova de proficiência para o ensino da Libras para a qual foi sorteado um tema de aula para cada cursista e, no outro dia, foi realizada a prova. A banca avaliadora foi composta de 02 profissionais surdos e 01 intérprete de Libras.

De acordo com os dados do relatório final do curso descritos por Oliveira (2017), 37 cursistas fizeram a prova de proficiência. Deste quantitativo, 32 foram aprovados, sendo 05 cursistas surdos.

\section{Metodologia sinalizada}

Nesta investigação, realizou-se uma pesquisa de campo de abordagem qualitativa. De acordo com Lüdke e André (1986, p. 11), "[...] a pesquisa qualitativa tem o ambiente natural com sua fonte direta de dados e o pesquisador como seu principal instrumento". Chizzotti (2009, p. 79) afirma que a abordagem qualitativa "[...] parte do fundamento de que há uma relação dinâmica entre o mundo real e o sujeito, uma interdependência viva entre o sujeito e o objeto, um vínculo indissociável entre o mundo objetivo e a subjetividade do sujeito".

Este estudo tem por base a Teoria das Representações Sociais, com o foco na educação inclusiva e nas representações dos egressos do curso de instrutores de Libras sobre a consolidação das políticas linguísticas, a partir de sua atuação como instrutores 
http://dx.doi.org/10.5902/1984686X38279

de Libras, isto é, na maneira em que elaboram e partilham simbologias significantes e construtivas acerca dessa consolidação.

As pesquisas com a Teoria das Representações Sociais tiveram sua origem no século XX com Moscovici (1981) e se desdobram em quatro abordagens:

(1) processual ou sociocultural representada por Denise Jodelet, principal colaboradora de Moscovici; (2) perspectiva relacional, mais sociológica, inaugurada por Willem Doise; (3) a estrutural desenvolvida por Jean-Claude Abric com ênfase no aspecto cognitivo-estrutural; e (4) dialógica de Marková voltada para a dimensão simbólica (SOUZA, 2009, p. 161).

$\mathrm{Na}$ análise das Representações Sociais sobre educação de surdos, utilizamos a abordagem processual, desenvolvida por Moscovici $(1981$; 2009) e aprofundada por Jodelet (1998) que visa "conhecer os processos de formação de uma representação social com o objetivo de buscar suas condições sociais de produção assim como as práticas sociais que as geram e as justificam" (ALVES-MOZZOTI; MAIA; MAGALHÃES 2010, p. 5).

A Representação Social é entendida como "[...] forma de conhecimento prático, de senso comum, que circula na sociedade. Esse conhecimento é constituído de conceitos e imagens sobre pessoas, papeis e fenômenos do cotidiano" (RANGEL, 2004, p. 66). Os processos de formação das Representações Sociais compreendem a Ancoragem e a Objetivação que fomentam a construção do núcleo figurativo, o qual, por sua vez, é constituído de estruturas figurativas e simbólicas (MOSCOVICI, 2009).

Nascimento explica que:

[...] a ancoragem é atribuição pela sociedade de uma escala de valores e preferências para um objeto social em função das interações sociais. [...] a objetivação pode ser vista nesse processo de formação das representações sociais como um recurso que o pensamento utiliza, denominado de naturalização, para tornar concretos, reais, conceitos abstratos. (NASCIMENTO, 2013, p. 52)

Assim, as ancoragens e objetivações serão vistas e problematizadas mediante as sinalizações dos egressos surdos do curso acerca das políticas linguísticas na Amazônia tocantina, no que tangente às suas formações e atuações como instrutores surdos.

Os critérios estabelecidos para participação da pesquisa foram: (1) ser aluno(a) surdo(a) egresso(a) do curso; (2) ter sido aprovado na prova de proficiência do curso; (3) estar atuando como instrutor de Libras; e (4) aceitar participar da pesquisa. Com base nesses critérios foram selecionados 04 sujeitos surdos egressos do curso de instrutores de Libras na Amazônia tocantina, sendo 03 mulheres e 01 homem. 
http://dx.doi.org/10.5902/1984686X38279

Os entrevistados assinaram o Termo de Consentimento Livre e Esclarecido (TCLE), permitindo a publicação de informações, recebendo, porém, nomes fictícios de militantes surdos pertencentes à comunidade surda brasileira, para ser mantido o anonimato, conforme o quadro a seguir.

Quadro 1 - Perfil dos entrevistados

\begin{tabular}{|c|c|c|c|}
\hline NOME FICTÍCIO & IDADE & FORMAÇÃO & FORMAÇÃO PROFISSINAL \\
\hline Karin & 38 & Pedagoga & Professora de Libras \\
\hline Gladis & 20 & Estudante & Instrutora de Libras \\
\hline Patrícia & 19 & Universitária & Instrutora de Libras \\
\hline Rodrigo & 20 & Estudante & Instrutora de Libras \\
\hline
\end{tabular}

Fonte: Elaborado pelas autoras, 2019.

$\mathrm{Na}$ sistematização e análise dos dados foram utilizadas técnicas da Análise de Conteúdos de Bardin (2010) e trabalhando "[...] o material acumulado, buscando-se destacar os principais achados da pesquisa" (LUDKE; ANDRÉ, 1986, p. 48), criando-se categorias temáticas: a importância do curso de instrutores de Libras na consolidação das políticas linguísticas; e atuação profissional do instrutor surdo: modelo linguístico e identitário, assim como foram utilizadas categorias analíticas, entre as quais: representações sociais, ancoragem e objetivação, que estão explicitadas no desenvolvimento do artigo.

\section{Resultados e discussões}

\section{Políticas Linguísticas na Educação de Surdos e o Instrutor Surdo}

As políticas linguísticas apresentam raízes nas políticas públicas, na medida em que se pautam em movimentos de reivindicações sociais e de lutas de direitos de segmentos sociais historicamente negados, entre os quais o das pessoas surdas.

Lenzi explica que as políticas públicas são:

Ações e programas que são desenvolvidos pelo Estado para garantir e colocar em prática direitos que são previstos na Constituição Federal e em outras leis. São medidas e programas criados pelos governos dedicados a garantir o bem-estar da população. Além desses direitos, outros que não estejam na lei podem vir a ser garantidos através de uma política pública. Isso pode acontecer com direitos que, com o passar do tempo, sejam identificados como uma necessidade da sociedade. (LENZI, 2018, p. 1) 
http://dx.doi.org/10.5902/1984686X38279

As políticas públicas, então, visam, por meio de legislações, programas e de estratégias de ações, garantir os direitos de todos os cidadãos, em termos de saúde, transporte, educação, entre outros.

Oliveira (2005) explica que, no Brasil, desde a Constituição de 1824, objetiva-se garantir a universalização do ensino básico, por meio do acesso ao saber escolar, caracterizando-se como um movimento pelo ensino público e gratuito. Visa-se garantir o direito à educação a todos os indivíduos como um direito à cidadania, na perspectiva de se afirmar como uma situação de "igualdade de direitos", centralizada nas questões de classe social e de diferenças individuais e culturais como problemáticas socioculturais.

Ao pensar nas políticas públicas, no campo da surdez, enfatiza-se a importância de um espaço e uma educação bilíngue para surdos e profissionais capacitados em Libras instrutores e intérpretes. Segundo Oliveira (2016, p. 382), as políticas linguísticas "[...] são uma área das políticas públicas, concebidas e executadas por instituições que têm ingerência na sociedade, como os Estados, os governos, as igrejas, as empresas, as ONGs, e até as famílias”. Nessa perspectiva,

A política linguística não é mais compreendida como uma intervenção na língua no âmbito de um Estado-nação, mas também está presente em quaisquer níveis que envolvam decisões relacionadas a línguas e suas variedades. Desse modo, essas decisões podem ser realizadas por diferentes agentes como indivíduos, instituições supragovernamentais, por exemplo, em diferentes espaços sociais como na família, em lugares públicos, no ambiente de trabalho (SOUZA; AFONSO, 2017, p. 41).

No campo da surdez, as políticas linguísticas são descritas, principalmente, pela Lei de Libras ํㅜ 10.436, de 24 de abril de 2002, e pelo Decreto ํㅜ 5.626, de 22 de dezembro de 2005, o qual legitima a Lei de Libras.

Lopes (2007) reafirma o pensamento de Wrigley (1996) ao mencionar que foi somente "[...] no final do XVIII que a surdez se torna um espaço de cultura e, por isso, de interesse para uma reflexão de cunho filosófico" (LOPES, 2007, p. 47). A partir desse momento, o sujeito Surdo começa a ser problematizado e conceituado por sua diferença linguística e não somente pela sua deficiência. Nessa perspectiva, a surdez se efetiva no debate sobre a diversidade, a pluralidade e a cultura. Dessa forma:

Não se trata, portanto, de simplesmente negar a surdez para começarmos a fazer um discurso da diferença surda; trata-se de pensar outras formas de significação que permitem a criação de elo entre semelhantes. É preciso compreender que uma distinção cultural sempre passa pela diferença (LOPES, 2007, p. 52). 
http://dx.doi.org/10.5902/1984686X38279

Autores como Klein (2004), Lopes (2007), Skliar (2010), destacam que, no momento em que a sociedade ancorou o surdo pelo ato de não ouvir e o materializou como incapaz, impossibilitou-se de observar outros elementos que constituíam o sujeito Surdo como: a Língua Brasileira de Sinais; a apreensão do mundo por suas experiências visuais; e o fato de serem sujeitos bilíngues, dentre outros.

Assim, esse reconhecimento da diferença linguística surda reafirma-se nas políticas linguísticas da Libras. Em 2002, a Libras ganha status de Língua e é reconhecida como meio de comunicação e/ou expressão utilizado pelo sujeito surdo. A Lei ํํ 10.436 destaca que:

Entende-se como Língua Brasileira de Sinais - Libras - a forma de comunicação e expressão, em que o sistema linguístico de natureza visualmotora, com estrutura gramatical própria, constitui um sistema linguístico de transmissão de ideias e fatos, oriundos de comunidades de pessoas surdas do Brasil (BRASIL, 2002, p. 1).

A Libras, ao ser reconhecida como língua pertencente à comunidade Surda, afirmase "como instrumento cultural" (LOPES, 2007, p. 28). A política linguística no campo da Libras tem por referência o Decreto $n^{0}$ 5.626/05, de 22 de dezembro de 2005, que regulamenta a Lei de Libras no 10.426/02 e reafirma ser esta a língua natural do sujeito surdo, demarcando o início de implantações desta política na área da inclusão educacional, social, linguística e saúde.

O Decreto no 5.626/2005 versa sobre as medidas destinadas para a formação de profissionais para atuação com sujeitos surdos como: professores bilíngues; professores de Libras e de Língua Portuguesa como L2 para surdos; instrutores e intérpretes de Libras. Nesse sentido, destacamos neste artigo dois pontos importantes do Decreto: a implementação da Libras como disciplina obrigatória nos cursos de licenciatura e o instrutor de Libras.

Esse decreto, também, destaca a inclusão da Libras como disciplina curricular nos cursos de formação de professores. No Art. $3^{\circ}$ estabelece que:

A Libras deve ser inserida como disciplina curricular obrigatória nos cursos de formação de professores para o exercício do magistério, em nível médio e superior, e nos cursos de Fonoaudiologia, de instituições de ensino, públicas e privadas, do sistema federal de ensino e dos sistemas de ensino dos Estados, do Distrito Federal e dos Municípios (BRASIL, 2005, p.1). 
http://dx.doi.org/10.5902/1984686X38279

O marco da inserção de disciplinas sobre a educação especial nos currículos de formação docente, neste caso a Educação dos Surdos, deu-se após a promulgação da Lei $n^{\circ}$ 10.436, que reconhece a Libras como língua oficial dos surdos. Em seu Art. 4ํㅡ, expressa a obrigatoriedade de as instituições de formação docente inserir em seus currículos a disciplina Libras.

Com a implantação da Libras nos cursos de formação de professor, espera-se que o processo de inclusão seja praticado com mais eficiência, haja visto que os futuros docentes terão conhecimento sobre a história dos surdos e os aspectos teóricos da língua, podendo atuar positivamente na construção do conhecimento dos discentes, além de facilitar a comunicação entre alunos e professores.

Assim, a implementação da disciplina de Libras nos cursos de licenciatura tem como medida formar profissionais mais inclusivos e com olhares holísticos acerca da diferença surda. Outro ponto de destaque apresentado pelo Decreto $n^{0} 5.626 / 05$ foi o instrutor de Libras que é o profissional certificado em nível médio, responsável pelo ensino da Língua Brasileira de Sinais nos espaços educacionais. A formação deste profissional pode ocorrer mediante:

Art. 6ำ A formação de instrutor de Libras, em nível médio, deve ser realizada por meio de: I - cursos de formação profissional; II - cursos de formação continuada promovidos por instituições de ensino superior; III - cursos de formação continuada promovidos por instituições credenciadas por secretarias de educação.§ $1^{\circ}$ A formação do instrutor de Libras pode ser realizada também por organizações da sociedade civil representativa da comunidade surda, desde que o certificado seja convalidado por pelo menos uma das instituições referidas nos incisos II e III (BRASIL, 2005, p. 2).

Faz-se necessário pontuar que no Art. 6 §2 "[...] as pessoas surdas terão prioridade nos cursos de formação previstos no caput' (BRASIL, 2005, p.2). Assim sendo, a preferência para o ensino da Libras, seja em nível médio e/ou superior, é do profissional surdo certificado mediante aos itens descritos no Art. 6 do Decreto de Libras (BRASIL, 2005).

Nesse sentido, optou-se em tratar do profissional instrutor de Libras Surdo. Gurgel (2004) menciona que o trabalho desse profissional não é apenas o ensino de uma língua, pois ele desempenha uma ação educativa, política, identitária e linguística, posto que sua presença no espaço educacional oportuniza ao educando Surdo o reconhecimento de sua língua e identidade, uma vez que o instrutor Surdo será o representante da Língua da pessoa Surda. 
http://dx.doi.org/10.5902/1984686X38279

Santos et al. destacam que:

O instrutor surdo é um educador que deve trazer para o espaço escolar os valores, aspectos culturais, emoções e percepções da ótica da pessoa surda. [...] a presença do instrutor surdo no contexto educacional é de suma importância, assim como o desenvolvimento de práticas que favoreçam o desenvolvimento de linguagem, sua constituição e identidade, além do aprendizado da Libras. (SANTOS et al, 2016, p. 129)

A presença do instrutor Surdo é de extrema relevância em todos os níveis de ensino, pois esse profissional, além de ensinar a Libras aos sujeitos pertencentes ao espaço educativo, materializa uma referência de modelo identitário e linguístico ao educando Surdo. Olhar o outro pelo prisma da diferença linguística e identitária se torna uma ação marcada pela alteridade, isto é, pelo reconhecimento da singularidade existencial de cada sujeito.

Desse modo, a presença desse profissional é vital na aprendizagem e no desenvolvimento linguístico, identitário, político e cultural do educando Surdo nos espaços formativos. Esse profissional apresenta-se no espaço educativo como o selo da diferença e das potencialidades do Eu-Surdo, ilustrando a todos que, se o Surdo estiver em um ambiente linguisticamente favorável para sua aprendizagem, conseguirá desenvolver suas potencialidades e tornar-se um sujeito autônomo, crítico e politizado.

O selo da diferença não coloca o Surdo enquanto ser superior ao mesmo que não aceita a marcação na inferioridade. O selo da diferença conceitua o surdo por sua singularidade, ou seja, ele não precisa da comparação com outro para ser Surdo: ele é o que é, por suas relações, por sua história de vida e por identificação linguística.

Oliveira (2005) explica que, por meio da compreensão do Outro como alteridade, o filósofo Enrique Dussel refuta o conceito de diferença que tem por base o princípio de identidade, cujo referencial é o dado pelo sistema, isto é, quando o Ser é a referência ao Não-Ser. Dussel (1980) estabelece o conceito de "diversidade dis-tinta", baseada na relação distinção-convergência de alteridade.

O ser humano "distinto por sua constituição real como coisa eventual ou livre, converge, se reúne, se aproxima de outros homens (...) O outro é alteridade de todo sistema possível, além do 'mesmo' que a totalidade sempre é (...) O outro se revela realmente como outro, em toda a acuidade de sua exterioridade, quando irrompe como o mais extremamente distinto, como o não habitual ou cotidiano, como o extraordinário, o enorme (fora da norma), como o pobre, o oprimido" (DUSSEL, 1980, p. 49). 
http://dx.doi.org/10.5902/1984686X38279

Assim, a exclusão social:

[...] se constitui num problema ético e político, o que implica, a partir do olhar de Dussel, não apenas reconhecer a existência de vítimas ou de oprimidos ou de abstrair conceitos e valores que reforçam a solidariedade, a justiça social, os direitos humanos, mas há necessidade de se problematizar as causas da exclusão a partir do reconhecimento do outro não só como excluído, mas também como sujeito, assumindo-se um compromisso ético com o outro, denunciando a exclusão e se apontando perspectivas de mudança (OLIVEIRA; DIAS, 2012, p. 102).

Reconhecer a alteridade da pessoa Surda parte do pressuposto de aceitá-la não somente como excluída por uma sociedade a qual busca o padrão da normalização, mas também como sujeito de sua própria história social e cultural. Dessa maneira, quando eu aceito o outro eu $\mathrm{o}$ aceito com todas suas particularidades, peculiaridades e individualidades, tendo sob ele o olhar da "[...] diferença dentro da diferença, uma visão mais complexa do diferente, para além do paradigma da diversidade" (FLEURI, 2006, p. 495).

No posicionamento conceitual da diferença surda, Lopes argumenta:

[...] que ela não se dá no fato de o indivíduo ser surdo, mas de este viver em comunidade e compartilhar, com seus pares, uma língua viso-gestual, uma forma de viver e de organizar o tempo e o espaço; enfim, é entre sujeitos semelhantes de uma mesma comunidade que os surdos são capazes de se colocar dentro do discurso da diferença cultural. (LOPES, 2007, p. 71)

Outrossim, compreende-se que o surdo precisa de outro(s) Surdo(s) para construir sua identidade de Surdo e isso ocorre por meio da partilha do encontro dialógico, afetivo, linguístico e identitário presente na comunidade surda. Soma-se a isso que "[...] os movimentos surdos, em prol da conquista de um espaço surdo, dos direitos de os surdos terem uma língua e de serem reconhecidos como um grupo cultural acentuaram-se no Brasil, a partir da década de 1990" (LOPES, 2007, p. 52).

Para tanto, os alunos Surdos nas escolas do campo necessitam ter contato com profissionais Surdos. A prática educativa de instrutores Surdos deve estar pautada na empatia com outros alunos Surdos, já que o instrutor Surdo poderá proporcionar uma prática educativa firmada na visualidade, metodologias apropriadas e flexíveis aos ensinos desses alunos.

Atualmente, para Lopes (2007, p. 79), “[...] muitos surdos adultos estão sendo referência para outros surdos e isso é uma forma de atualizar a luta surda, mostrando as sofisticações nas estratégias de dominação forjadas nos dias de hoje". Dessa forma, o instrutor surdo não seria apenas importante numa perspectiva de modelo educacional por ser 
http://dx.doi.org/10.5902/1984686X38279

usuário da Libras, mas também por ancorar suas ações educativas nas identidades surdas, no discurso das diferenças e na resiliência surda. De acordo com Lopes (2007, p. 81), "[...] hoje as pessoas e profissionais surdos [...] estão servindo de referência para a comunidade surda" no tocante a seu processo de escolarização e nas suas relações eu-outro na sociedade.

Pensar na educação de surdos na ótica do próprio surdo é "[...] tratar de produzir uma política de significações que gere um outro mecanismo de participação dos próprios surdos no processo de transformação pedagógica" (SKILIAR, 2010, p. 14). Parte-se, então, da ideia de alteridade, que considera o "outro" como diferente não como oposto ao "normal", mas como é, em seu modo mais singular, reconhece-o a partir da consciência de sua diferença (SKLIAR, 2006). É nesse bojo de luta pelo reconhecimento da identidade linguística que se faz necessária a presença do instrutor Surdo nas escolas do campo, pois se compreende que, "[...] ao se organizarem, os surdos lutam e resistem aos modelos dos saberes e à própria ordem dos discursos oficiais" (LOPES, 2007, p. 52).

Entretanto, Santos e Gurgel (2009) chamam a atenção acerca dos fatores os quais restringem a atuação deste profissional no contexto escolar como: a formação inicial e continuada. Dessa maneira, é imprescindível a formação continuada e em serviço a estes profissionais, bem como a oferta de cursos para certificação, qualificação e atuação desse profissional, como o qual foi ofertado pelo GESAT, em 2017.

A formação de instrutores Libras ancora, no ensino da Libras, uma essência das políticas linguísticas e materializa, na formação de profissionais, a difusão dessa língua. Nessa perspectiva, o instrutor Surdo ilustra sua identidade na dimensão existencial e profissional, ao afirmar sua singularidade linguística.

O curso realizado em 2017, assim, apresentava em seu corpus de desenvolvimento, uma ação afirmativa por meio de uma política linguística que é a consolidação desse profissional na Amazônia tocantina. Portanto, faz-se necessário refletir e analisar as ancoragens e objetivações presentes nos dizeres dos entrevistados.

Quanto à importância do referido curso, apresentam-se as seguintes dimensões: formação aos surdos na sua própria língua; metodologias visuais; localização do curso; e um espaço inclusivo. Assim, ilustram-se as ancoragens e objetivações presentes nas falas de Karin, Patrícia, Gladis e Rodrigo, no quadro a seguir. 
http://dx.doi.org/10.5902/1984686X38279

Quadro 2 - A importância do curso de instrutores de Libras na consolidação das políticas linguísticas

\begin{tabular}{|c|c|l|}
\hline ENTREVISTADO & \multicolumn{1}{|c|}{ ANCORAGEM } & \multicolumn{1}{c|}{ OBJETIVAÇÃO } \\
\hline Karin & $\begin{array}{c}\text { Formação aos surdos n } \\
\text { língua }\end{array}$ & $\begin{array}{l}\text { Os professores que ministraram os módulos eram surdos. Aprender } \\
\text { nossa língua e não perdemos informações }\end{array}$ \\
\hline Patrícia & Curso no interior & $\begin{array}{l}\text { A formação foi boa por terem professores surdos, materiais aces visua } \\
\text { mas, principalmente, por ser no interior, porque às vezes para faz } \\
\text { formações precisamos ir para Belém. Esse curso, não. Foi no nosso } \\
\text { ouvintes }\end{array}$ \\
\hline Gladis & $\begin{array}{l}\text { Metodologia para o ensino de Libras através da pedagogia vino estratégias para ensinarmos a Libras para os su } \\
\text { Rodrigo }\end{array}$ & $\begin{array}{l}\text { As aulas foram em libras ministradas por professores surdos e } \\
\text { presença de alunos surdos e ouvintes aprendendo como ensinar } \\
\text { nas escolas e em outros espaços. }\end{array}$ \\
\hline
\end{tabular}

Fonte: Elaborado pelas autoras, 2019.

Karin destacou a importância de a formação aos Surdos acontecer na sua língua, isto é, na Libras. No momento em que as aulas foram ministradas em Libras, inverteu-se a lógica do uso da língua majoritária no Brasil, a Língua Portuguesa, e, assim, criou-se um espaço acolhedor e propício para apreensão do conhecimento mediada pela Libras.

Desse modo, a aprendizagem tornou-se direta, face a face entre os sujeitos presentes no espaço formativo por meio da relação dialógica, autêntica e recíproca com o outro. O professor Surdo proporcionou aos alunos Surdos a oportunidade de aprender em sua língua e a configuração de um espaço efetivamente bilíngue e, aos alunos ouvintes, a imersão linguística na Libras e a oportunidade de avaliar o processo de inclusão através da alteridade.

Entretanto, no processo de escolarização nem sempre o ambiente é linguisticamente favorável para o seu desenvolvimento e aprendizagem, uma vez que o educando Surdo "[...] não é atendido em sua condição sociolinguística especial, não são feitas alterações metodológicas que levem em conta a surdez, e o currículo não é repensado, culminando em um desajuste socioeducacional" (LACERDA; LODI, 2009, p. 15).

No tocante às metodologias utilizadas pelos professores surdos, Patrícia informa que foram ancoradas e objetivadas na pedagogia visual, a qual "[...] inclui a Língua de Sinais como um dos recursos dentro da comunicação e da educação" (CAMPELLO, 2007, p. 130).

Nessa perspectiva, os professores rompem com a realidade educacional, da ausência de materiais pedagógicos voltados aos educandos surdos, em que a imagem não é tida como metodologia no processo de aprendizagem fazendo com que os alunos Surdos não compreendam o conteúdo dado e nem consigam acompanhar os demais 
http://dx.doi.org/10.5902/1984686X38279

educandos ouvintes, já que a metodologia não favorece suas particularidades e não garante a efetivação de sua política linguística.

Campello (2007, p. 113) infere que a Libras "[...] inscreve-se no lugar da visualidade e, sem dúvida, encontra na imagem uma grande aliada junto às propostas educacionais e às práticas sociais do aluno surdo". Somando-se a esse conceito, Oliveira (2013) defende o uso de práticas pedagógicas que respeitem as singularidades linguísticas do educando surdo, ao afirmar que: "[...] a aprendizagem só dará de maneira efetiva e satisfatória, se os usos das metodologias adotadas no ensino estiverem de acordo com as necessidades dos educandos surdos, em ordem psíquica, social, afetiva, linguística e cognitiva" (OLIVEIRA, 2013, p. 495).

Rodrigo corrobora com as representações sociais de Patrícia acerca da importância das metodologias utilizadas no curso serem acessíveis ao surdo, entretanto problematiza as escolhas metodológicas para além da prática educativa, devendo voltar-se também para ação humanizadora do outro (professor surdo) e oportunizar um espaço inclusivo. Dessa forma, ancora a inclusão na convivência com sujeitos diferentes de si e do outro, mas que compartilham saberes e afetos como já bem colocado por Oliveira (2015):

A educação inclusiva traz em sua essência a convivência de sujeitos plurais em um ambiente educativo, em que partindo da diferença como alteridade, os sujeitos com ou sem deficiência, possam aprender e construir suas identidades através do encontro dialógico, amoroso e afetivo com o outro. (OLIVEIRA, 2015, p. 178)

Conviver com o outro, diferente de mim, é possibilitar-me a aprender, a dialogar e a experienciar o mundo por meio, não do meu ou do seu olhar, mas do entre, da relação, ou seja, do nosso olhar. Tal ação está imersa em rios e saberes da alteridade, uma vez que "[...] o exercício da alteridade impregna em cada indivíduo o amor necessário ao outro, a si mesmo e a vida" (OLIVEIRA, 2015, p. 156).

Por fim, Gladis somatiza a importância do curso de instrutores de Libras na Amazônia tocantina como consolidação das políticas linguísticas expressas na Lei e no Decreto de Libras, em conformidade com a singularidade do Surdo (aulas em Libras), professores Surdos (prioridade para o ensino da língua) e metodologias acessíveis (estratégias no ensino do Surdo). 
http://dx.doi.org/10.5902/1984686X38279

Outro destaque importante, na representação social de Gladis, é em relação ao espaço formativo onde ocorreu o curso, destacando o fato de o curso acontecer no interior. A entrevistada informou: "[...] porque às vezes para fazermos formações precisamos ir à Belém. Esse curso, não. Foi no nosso lugar".

Oliveira (2017) destaca que muitos sujeitos surdos do campo não têm acesso às formações iniciais e continuadas, uma vez que os espaços formativos se concentram na cidade. Isso significa que esse sujeito, na maioria dos casos, fica impossibilitado de participar de formações, em decorrência da distância e dos altos custos financeiros. Dessa forma, oportunizar a formação a estes sujeitos, no seu lugar de pertencimento, é garantir o acesso, partilhar saberes e reconhecer que o campo e a Amazônia não são lugares de atraso, mas sim de uma rica pluralidade linguística, cultural e social.

Significa oportunizar à pessoa surda, que foi negada pelpois me certo seu corpo deficiente, pela sua língua, enquanto língua subalterna e sujeito amazônico: o direito de se formar, de dizer sua palavra, a sua verdade e de se firmar no cenário nacional enquanto um ser social, mediante a sua integralidade existencial, social, cultural e linguística. Tal concepção ética-política-educativa com o outro, enquanto ser criador, fazedor e recriador de cultura está presente nas sementes da práxis freireana, as quais hoje se materializam nas formações desenvolvidas pelo GESAT.

A formação traz a discussão do ser humano na sua cultura respeitando suas culturas, respeitando as diferenças e valorizando os saberes dos diversos segmentos culturais. Tal formação fala de eticidade, de gênero, de língua, que é falar do ser humano, contextualizado em uma cultura em processo de construção. O fazer docente desenvolvido no curso, no princípio freireano, parte da premissa de o ensinar se interligar ao respeito, à alteridade e ao diálogo, tendo os educandos e educadores o direito de dizer a palavra e, assim, partilhar e construir novos saberes. Freire descreve que:

[...] ensinar e aprender se vão dando de tal maneira que quem ensina aprende, de um lado, porque reconhece um conhecimento antes aprendido e, de outro, porque, observando a maneira como a curiosidade do aluno aprendiz trabalha para apreender [...], o ensinante se ajuda a descobrir incertezas, acertos, equívocos. (FREIRE, 1993, p. 27)

No processo de ensino-aprendizagem o educador e o educando são sujeitos do conhecimento e aprendentes. $\mathrm{Na}$ ação educativa há partilha de saberes, porque, para Freire (1993), todos sabem alguma coisa e têm sua leitura de mundo e experiências de vida. Na matriz freireana, a educação e o ensino precisam estar conectados à cultura, à eticidade e à 
http://dx.doi.org/10.5902/1984686X38279

criticidade. Tais elementos se mostram presentes na fala de Patrícia: "[...] aprendi no curso não somente metodologias acessíveis para o ensino de Libras, mas aprendi também sobre a militância surda e a ocupar nossos espaços no ensino da língua" (ENTREVISTADA PATRÍCIA, 2018).

Com base nessas representações sociais, o curso de instrutores de libras inverteu a lógica da educação adaptada e urbanocêntrica para uma formação contextualizada na realidade local com o uso da Libras e valorização dos saberes dos sujeitos surdos em formação.

\section{Atuação profissional do instrutor surdo: modelo linguístico e identitário}

Segundo Lopes (2007), a partir dos anos 1980, o sujeito Surdo começou a ser representado como pertencente a um grupo étnico minoritário. A surdez, então, começou a ser vista pelo selo da diferença e não mais pela falta e/ou dano biológico. Nessa perspectiva, Klein (2004) infere:

[...] a surdez como diferença refere-se a uma minoria linguística que faz uso de uma outra língua, a Língua de Sinais. Remete-se à necessidade de se pensar em políticas públicas que atendam as especificidades da comunidade surda e que não prescindam da participação das lideranças surdas nos debates sobre suas realidades sociais, culturais, educacionais, de trabalho, de lazer entre outros (KLEIN, 2004, p. 89).

Assim, somente a partir da representação social da surdez como traço cultural foi possível enxergar o sujeito Surdo não mais pela ótica da correção acerca de um corpo com dano, mas como sujeito social capaz de ser ensinado, de trabalhar e viver plenamente na sociedade. Nessa perspectiva, os Surdos foram ocupando os espaços sociais por meio da resistência e militância presentes nos movimentos Surdos ${ }^{5}$, o que impulsionou as políticas linguísticas afirmativas a esta comunidade.

A relação entre o Surdo e o mercado de trabalho é um tema relativamente recente nos Estudos Surdos ${ }^{6}$. De acordo com Klein (2010, p. 79), o assunto começa a ser tratado no momento que a surdez se configura como diferença cultural e materializa-se no trabalho um sentido libertador, "[...] levando o sujeito surdo à conquista da autonomia". Em relação à atuação profissional, mediante a formação de instrutores de Libras, os entrevistados demarcam: a atuação como professora de Libras para crianças e adultos, o ensino da língua nos cursos básicos de Libras e o modelo identitário e linguístico, conforme descrito nas ancoragens e objetivações presentes no quadro a seguir. 
http://dx.doi.org/10.5902/1984686X38279

Quadro 3 - Atuação profissional do instrutor surdo: modelo linguístico e identitário

\begin{tabular}{|c|l|l|}
\hline ENTREVISTADO & ANCORAGEM & \multicolumn{1}{c|}{ OBJETIVAÇÃO } \\
\hline Karin & Ensino de Libras & $\begin{array}{l}\text { Trabalho com crianças e adultos surdos na escola. Eu ensino } \\
\text { crianças que não tem contato com a Libras, porque seus pais } \\
\text { são ouvintes [...] ensino um adulto surdo de 41 anos na EJA que, } \\
\text { também, não teve acesso a Libras quando criança. }\end{array}$ \\
\hline Patrícia & Professora e militante & $\begin{array}{l}\text { [..] Eu ensino nos cursos de Libras do GESAT aos ouvintes que } \\
\text { não sabem e aos surdos que estão vendo a Libras só agora [...] } \\
\text { Eu me esforço para mostrar que os surdos podem chegar aonde } \\
\text { quiserem e que precisamos lutar pelos nossos direitos. }\end{array}$ \\
\hline Gladis & Libras no interior & $\begin{array}{l}\text { Eu ensino Libras no curso do GESAT. Estou no curso básico de } \\
\text { Libras em Oeiras [...] Lá estou ensinando 04 surdos e ouvintes. }\end{array}$ \\
\hline Rodrigo & Professor surdo & $\begin{array}{l}\text { Eu ensino em dois cursos de Libras. Ensino Libras no curso } \\
\text { básico, intermediário e avança. O curso de instrutor foi } \\
\text { importante para mim, pois me certificou e me deu uma profissão. }\end{array}$ \\
\hline
\end{tabular}

Fonte: Elaborado pelas autoras, 2019.

A atuação profissional de Karin se deu por intermédio de um contrato com a prefeitura de seu município, onde desempenha o ensino de Libras para crianças e adultos Surdos. Karin destaca em sua ação educativa com crianças Surdas a necessidade de alfabetizá-las em Libras, uma vez que é a língua materna do Surdo (BRASIL, 2005).

A este respeito, Gurgel (2004) destaca que o instrutor surdo assume o papel de extrema importância no ensino de crianças surdas, posto que a maioria delas se encontra em lares ouvintes, cujos familiares desconhecem a Libras. Assim, o instrutor Surdo tornase um modelo linguístico para as crianças e possibilita o ensino da língua desde a tenra idade.

No campo da Educação de Jovens e Adultos (EJA) não é diferente, pois a presença do instrutor Surdo provoca no educando a possibilidade do ensino e do reconhecimento enquanto sujeito pertencente a uma minoria linguística. Sobre esta questão, Marques destaca:

[...] a inserção de um professor surdo para ministrar aulas aos seus semelhantes seria a opção ideal além da língua; os alunos têm acesso à cultura e espelham-se no professor como motivação de sucesso e percebem que o mundo dos vencedores não é só de pessoas não surdas. (MARQUES, 2007, p. 143)

A importância dessa identificação com o professional é de extrema valia, porque, para a criança, é a possibilidade de se desenvolver na língua desde cedo e, para o adulto, a oportunidade, antes talvez negada, de vivenciar sua diferença linguística. Além disso, destaca-se a ascensão social por meio da educação de um sujeito Surdo tendo acesso ao mercado de trabalho. 
http://dx.doi.org/10.5902/1984686X38279

Gladis corrobora com o dizer de Karin ao ilustrar que está ensinando 04 (quatro) surdos no curso de Libras ofertado pelo GESAT, e pontua: "[...] quem sabe elas possam depois ensinar outros surdos e se tornarem professores" (ENTREVISTADA GLADIS, 2018). Assim, entende-se que o instrutor Surdo pode potencializar as escolhas profissionais e as atitudes de resistências de seus alunos Surdos, ao se apresentar como um espelho profissional e humano que é admirado e, quem sabe, aquele que inspira outros sujeitos.

O curso de instrutores de Libras na Amazônia tocantina oportunizou a esses sujeitos o ingresso ao mercado de trabalho, como bem colocado pelo entrevistado Rodrigo: "o curso de instrutor foi importante para mim, pois me certificou e me deu uma profissão". Nesse sentido, ilustra-se a relevância dessa formação na vida humana e profissional dos sujeitos Surdos da Amazônia tocantina, uma vez que proporcionou formação a eles, a qual talvez não tivessem e, por conseguinte, a possibilidade de profissionalizar-se na cidade.

Outra representação significativa fez-se presente no dizer de Patrícia. A sua fala está impregnada de esperanças, sonhos e lutas e centraliza-se na resistência e militância surda. Portanto, seu ensino não está desconectado do fazer político, crítico e ativo no reconhecimento do ser surdo, como ser mais e como potência humana fazedora de sua história.

Patrícia, ao objetivar que se "[...] esforça para mostrar que os surdos podem chegar aonde quiserem e que precisamos lutar pelos nossos direitos", ancora sua representação na militância surda e nos direitos linguísticos. Oliveira (2018, p. 66) destaca que "[...] não há possibilidade de construção de conhecimento e nem de prática educativa se não tivermos uma postura militante e engajada [...] o conhecimento se produz na militância e no engajamento".

No campo dos Estudos Surdos e do movimento surdo não é diferente, pois Klein (2004) já ilustrava em seus estudos a importância das associações de Surdos frente à luta contra as práticas ouvintistas, normalizadoras e colonizadoras do Eu-Surdo. A representação social de Patrícia é imersa em um campo simbólico de luta materializada em ações educativas críticas, praxiológicas e políticas, que coloca no centro do debate, da formação educativa e identitária o Surdo do campo em suas marcações culturais e linguísticas. 
http://dx.doi.org/10.5902/1984686X38279

\section{Sinalização final}

A formação de instrutores de Libras, promovida pelo Grupo de Estudos Surdos na Amazônia Tocantina, ancorou a Libras como uma ação afirmativa de uma política linguística no campo das diferenças. A pesquisa ilustrou que os entrevistados marcaram sua atuação como: consolidação das políticas públicas e linguísticas na área da Libras e como modelo identitário para o ensino de surdos, pautado no reconhecimento da diferença como alteridade e no bilinguismo.

Além desse resultado, a pesquisa revelou que, após a finalização do curso de 05 egressos surdos, 04 estão atuando como instrutores de Libras. Isso demarca as contribuições do curso na formação e capacitação desses profissionais surdos pertencentes à Amazônia tocantina. Analisa-se, também, a importância da presença do instrutor Surdo de Libras nas escolas regulares para a efetivação de práticas inclusivas, que garantam ao aluno Surdo encontrar condições de estabelecer interações sociais a partir de modelos linguísticos e identitários.

Nessa perspectiva, o curso de instrutores de Libras na Amazônia tocantina não reduz sua importância a formação inicial de profissionais Surdos, como também vislumbra a possibilidade do favorecimento de construções de práticas escolares inclusivas, que atentem para a singularidade dos processos de aprendizagem do aluno Surdo, mediante a atuação de um profissional Surdo, formado em um curso que respeite o seu lugar, a sua cultura, a sua identidade e que possibilite sua vocação ontológica de ser-mais.

Patrícia, Gladis e Rodrigo atuam na formação de profissionais bilíngues, mediante aos cursos básicos e avançados de Libras. Tal prática educativa favorece a compreensão, por meio dos cursistas, de que os surdos apresentam capacidade e que podem desempenhar funções no âmbito social e educacional.

Os cursistas podem, assim, ressignificar suas representações sociais sobre os Surdos, mediante a prática educativa do instrutor Surdo, isto é, enxergar esse outro surdo pelo prisma da diferença linguística, identitária e cultural, o que oportunizará a esse cursista tanto realizar uma práxis, como o represente e o ensine mediante a outros elementos que constituem o sujeito Surdo, como: a Língua Brasileira de Sinais.

Karin, por sua vez, exerce uma função importantíssima, que é o ensino de Libras a crianças, jovens e adultos surdos. Esse ensino possibilita o favorecimento de construções de práticas escolares inclusivas, como também a apreensão da língua do sujeito Surdo, como já preveem as políticas públicas e linguísticas. Ela, ao desenvolver o ensino de 
http://dx.doi.org/10.5902/1984686X38279

Libras, materializa-se enquanto modelo ao aluno Surdo, tanto de língua quanto de identidade.

Por fim, a pesquisa apontou que o instrutor surdo não seria apenas importante em uma perspectiva educativa, mas também enquanto um modelo identitário, afetivo e linguístico para o educando Surdo, na medida em que esse profissional compreende as singularidades do olhar da diferença como alteridade, pois é capaz de apreender as especificidades do outro-Surdo por ser um sujeito bilíngue e usuário da Libras.

\section{Referências}

ALMEIDA, Rogério. Amazônia, Pará e o mundo das do Baixo Tocantins. Estud. av., n. 68, p. 291-298, 2010. Disponível em: http://www.scielo.br/scielo.php?script= sci_arttext\&pid=S0103-40142010000100020. Acesso em: 01 dez. 2018.

ALVEZ-MAZZOTTI, Alda Judith; MAGALHÃES, Edith Maria Marques; MAIA, Helenice. Representações sociais de trabalho docente: significados atribuídos a dedicação por professores das séries iniciais e seus formadores. In: SEMINÁRIO DO TRABALHO, 7, 2010, São Paulo. Anais [eletrônicos]. São Paulo: UNESP, 2010. Disponível em: http://www.estudosdotrabalho.org/anais-vii-7-seminario-trabalhoret-2010. Acesso em: 10 abr. 2019.

BARDIN, Laurence. Análise de conteúdo. Lisboa, Portugal: Edições 70, 2010.

BRASIL. Casa Civil. Lei n. 10436, de 24 de abril de 2002. Dispõe sobre a língua de Sinais e outras providências. Brasília, DF, 2002. Disponível em: http://www.planalto. gov.br/ccivil_03/Leis/2002/L10436.htm. Acesso em: 28 fev. 2019.

BRASIL. Decreto n. 5.626, de 22 de dezembro de 2005. Regulamenta a Lei n. 10.436, de 24 de abril de 2002, que dispõe sobre a Língua Brasileira de Sinais - Libras. Brasília, DF, 2005. Disponível em: http://www.planalto.gov.br/ccivil_03/_ato2004.../2005/ decreto/d5626.htm. Acesso em: 08 fev. 2019.

CAMPELLO, Ana Regina e Souza. Pedagogia Visual / Sinal na Educação dos Surdos. In: QUADROS, Ronice Muller de; PERLIN, Gladis (org.). Estudos Surdos II. Petrópolis, RJ: Arara Azul, 2007. p. 100-131.

CHIZZOTTI, Antônio. Pesquisa em ciências humanas e sociais. 10. ed. São Paulo: Cortez, 2009.

DOZIART, Ana. O outro da educação: pensando a surdez com base nos temas Identidades/Diferença, Currículo e Inclusão. Petrópolis, RJ: Vozes, 2009.

DUSSEL, Enrique. Filosofia da Libertação na América Latina. 2.ed. São Paulo: Loyola. 1980. 
http://dx.doi.org/10.5902/1984686X38279

FLEURI, Reinaldo Matias. Políticas da Diferença: Para além dos Estereótipos na Prática Educacional. Educ. Soc., Campinas, v. 27, n. 95, p. 495-520, maio/ago. 2006. Disponível em: http://www.scielo.br/pdf/es/v27n95/a09v2795.pdf. Acesso em: 22 jan. 2019.

FREIRE, Paulo. Professora sim, tia não: cartas a quem ousa ensinar. São Paulo: Olho d'Água, 1993.

GURGEL, Taís Margutii do Amaral. O papel do instrutor surdo na promoção da vivência da língua de sinais por crianças surdas. 2004. 90 f. Dissertação (Mestrado em Educação) - Universidade Metodista de Piracicaba, Piracicaba, 2004.

JODELET, Denise. A alteridade como produto e processo psicossocial. In: JODELET, D. et al. (org.). Representando a alteridade. Petrópolis, RJ: Vozes, 1998. p. 47-67.

KLEIN, Madalena. Cultura Surda e a inclusão no mercado de trabalho. In: THOMA, Adriana da Silva; LOPES, Maura Corcini. (org.). A invenção da surdez: cultura, alteridade, identidade e diferença no campo da educação. Santa Cruz do Sul: EDUNISC, 2004. p. 83-102.

KLEIN. Os discursos sobre surdez, trabalho e educação e a formação do surdo trabalhador. In: SKLIAR, Carlos. (org.). A surdez: um olhar sobre a diferença. Porto alegre: Mediação, 2010. p. 75-92.

LACERDA, Cristina Broglia Feitosa de. O intérprete de língua de sinais no contexto de uma sala de aula ouvintes: problematizando a questão. In: LACERDA, Cristina Broglia Feitosa de; GOES, Maria Cecilia Rafael de. (org.). Surdez: processos educativos e subjetividade. São Paulo: Lovise, 2000. p. 51-84.

LACERDA. LODI, Ana Claudia Balieiro. A inclusão escolar bilíngue de alunos surdos: princípios, breve histórico e perspectivas. In: LODI, Ana Claudia Balieiro; LACERDA, Cristina Broglia Feitosa de. (org.) Uma escola duas línguas- letramento em língua portuguesa e língua de sinais nas etapas iniciais de escolarização. Porto Alegre: Mediação, 2009. p. 143-160.

LENZI, Tié. O que são as políticas públicas? Toda Política, 26 abr. de 2018. Disponível em: https://www.todapolitica.com/politicas-publicas. Acesso em: 12 mar. 2019.

LIMA, Niédja Maria Ferreira. Inclusão escolar de surdos: o dito e feito. In: DORZIAT, Ana. (org.). Estudos surdos diferentes olhares. Porto Alegre: Mediação, 2011. p. 141-170.

LOPES, Maura Corcini. Surdez e Educação. Belo horizonte: Autêntica, 2007.

LUDKE, Menga; ANDRÉ, Marli. Pesquisa em educação: abordagens qualitativas. São Paulo: EPUD, 1986.

MARQUES, Rodrigo Rosso. Educação de Jovens e adultos: um diálogo sobre a educação e o aluno surdo. In: QUADROS, Ronice Muller de; PERLIN, Gladis. (org). Estudos

Surdos II. Petrópolis, RJ: Arara Azul, 2007. p. 132-149. 
http://dx.doi.org/10.5902/1984686X38279

MOSCOVICI, Serge. A representação social da psicanálise. Rio de Janeiro: Zahar, 1981.

MOSCOVICI, Serge. Representações sociais: investigações em psicologia social. 5. ed. Petrópolis, RJ: Vozes, 2009.

NASCIMENTO, Ivani Pinto. Articulações sobre o campo das representações sociais. In: ORNELLAS, Maria de Lourdes Soares (org.). Representações Sociais e educação: letras imagéticas. Salvador: EDUFBA, 2013. p. 35-68.

OLIVEIRA, Gilvan Müller de. Políticas Linguísticas: uma entrevista com Gilvan Müller de Oliveira. ReVEL, v. 14, n. 26, 2016. p. 382-399. Disponível em: http://www.revel.inf.br/ files/e92f933a3b0ca404b70a1698852e4ebd.pdf. Acesso: 26 fev. 2019.

OLIVEIRA, Ivanilde Apoluceno de. Saberes, imaginários e representações na

Educação Especial: a problemática ética da "diferença" e da exclusão social. 2.ed. Petrópolis, RJ: Vozes, 2005.

OLIVEIRA, Ivanilde Apoluceno. DIAS, Alder Sousa. Ética da Libertação de Enrique Dussel: caminho de superação do irracionalismo moderno e da exclusão social.

Conjectura, Caxias do Sul, v. 17, n. 3, p. 90-106, set./dez. 2012. Disponível em: http://www.ucs.br/etc/revistas/index.php/conjectura/article/view/1798/1129. Acesso em: 22 mar. 2019.

OLIVEIRA, Luiz Fernandes de. Educação e militância decolonial. Rio de Janeiro: Selo Novo, 2018.

OLIVEIRA, Waldma Maíra Menezes de. A importância das metodologias no ensino de jovens e adultos surdos. In: SEMINÁRIO NACIONAL DO INES, 18. 2013, Rio de Janeiro. Anais... Rio de Janeiro: INES, 2013. p. 483-496.

OLIVEIRA, Waldma Maíra Menezes de. Representações Sociais de educandos surdos sobre a atuação do Intérprete Educacional no Ensino Superior. 2015. 236 f.

Dissertação (Mestrado em Educação) - Universidade do Estado do Pará, Belém, 2015.

OLIVEIRA, Waldma Maíra Menezes de. Instrutores de Libras na Amazônia Tocantina. Projeto de extensão desenvolvido pelo Programa de Apoio a projetos de Intervenção Metodológica. Cametá: GESAT/UFPA, 2017.

RANGEL, Mary. A pesquisa de Representação Social como forma de enfrentamento de problemas socioeducacionais. Aparecida São Paulo: Ideias e Letras, 2004.

SANTOS, Lara Ferreira dos Santos; GURGEL, Taís Margutti do Amaral. O instrutor surdo em uma escola inclusiva bilíngue. In: LODI, Ana Claudia Balieiro; LACERDA, Cristina Broglia Feitosa de (org.) Uma escola duas línguas: letramento em língua portuguesa e língua de sinais nas etapas iniciais de escolarização. Porto Alegre: Mediação, 2009. p. 5164. 
SANTOS, Lara Ferreira dos. et al. O instrutor surdo: caminhos para uma atuação reflexiva e responsável. In: LACERDA, Cristina Broglia Feitosa de; SANTOS, Lara Ferreira dos; MARTINS, Vanessa Regina de (org.). Escola e diferença: caminhos para educação bilíngue de surdos. São Carlos: EdUFSCar, 2016. p. 127-148.

SKLIAR, Carlos. A inclusão que é "nossa e a diferença que é do "outro". In: RODRIGUES, David (org.). Inclusão e educação: doze olhares sobre educação inclusiva. São Paulo: Summus, 2006. p. 16-34.

SKLIAR, Carlos. Os estudos surdos em educação: problematizando a normalidade. In: SKLIAR, Carlos (org.). A surdez: um olhar sobre a diferença. Porto Alegre: Mediação, 2010. p. 7-32.

SOUSA, Socorro Cláudia Tavares de; AFONSO, Lília dos Anjos. Políticas linguísticas sobre a Libras: as crenças dos estudantes de letras. Revista de Letras, Fortaleza, v. 2, n. 35, jun. 2017. Disponível em: http://www.periodicos.ufc.br/revletras/article/view/19335. Acesso em: 26 mar. 2019.

SOUZA, Roseane Rabelo. Representações sociais de professores sobre a inclusão escolar de alunos com necessidades especiais. 2009. 164 f. Dissertação (Mestrado em Educação) - Universidade do Estado do Pará, Belém, 2009. Disponível em: http://www.page.uepa.br/mestradoeducacao. Acesso em: 04 fev. 2019.

WRIGLEY, Owen. The politicis of deafness. Washington: Gallaudet University Press, 1996.

\section{Notas}

${ }^{1}$ A terminologia Surdo (com "S" maiúsculo) foi adotada neste artigo, pois refere-se ao Surdo pela sua diferença linguística, identitária e cultural.

${ }^{2}$ O Grupo de Estudos Surdos na Amazônia Tocantina (GESAT) foi cadastrado no CNPq no dia 09 de julho de 2015. Apresenta como objetivo desenvolver produções científicas, tecnológicas e artísticas - culturais pautadas em estudos sobre surdez em âmbito da diversidade, educação de surdos, diferença com alteridade e das relações do outro surdo com o outro ouvinte na Amazônia Tocantina.

3 De acordo com Almeida (2009), o cotidiano no mundo das águas da microrregião de Cametá, mais conhecida como baixo Tocantins ou Amazônia tocantina, é organizado pelos rios Moju, Pará e o caudaloso Tocantins. Sete municípios compõem a região: Abaetetuba, Igarapé-Miri, Limoeiro do Ajuru, Cametá, Mocajuba, Baião e Oeiras do Pará.

\footnotetext{
4 A cidade de Cametá, que está localizada à margem esquerda do rio Tocantins, num espaço que compreende cerca de $3 \mathrm{~km}$ de extensão. Sua população é estimada, de acordo com o último censo, em 134.100 habitantes. A cidade se limita, ao norte, com o município de Limoeiro do Ajuru, ao sul, com Mocajuba, ao leste, com Igarapé Mirim e, ao oeste, com Oeiras do Pará. Fica numa distância de aproximadamente $236 \mathrm{~km}$ da região metropolitana de Belém (PA).
} 
http://dx.doi.org/10.5902/1984686X38279

5 "Movimentos surdos aqui são entendidos como movimentos sociais articulados a partir de aspirações, reivindicações, lutas das pessoas surdas no sentido do reconhecimento de sua língua, de sua cultura" (KLEIN, 2010, p. 75).

${ }^{6}$ Para Skliar (2010, p. 30), "Os estudos Surdos em Educação podem ser pensados como um território de investigação educacional e de proposições políticas que, através de um conjunto de concepções linguísticas, culturais, comunitárias e de identidades, definem uma particular apropriação com o conhecimento e com os discursos sobre a surdez".

\section{Correspondência}

Waldma Maira Menezes de Oliveira - Universidade do Estado do Pará, Centro de Ciências Sociais e Educação, Departamento de Filosofia e Ciências Sociais, Rua do Una, 156, Belém, Pará - Brasil. CEP: 66050-540

This work is licensed under a Creative Commons Attribution-NonCommercial 4.0 International (CC BY-NC 4.0) 